\title{
Necessity of Getting Involved in Learning Special English of Civil Engineering
}

\author{
Zhijia Pan \\ Department of Urban Construction \\ Wuchang Shouyi University \\ Wuhan, China
}

\author{
Haiqing Yuan \\ Department of Urban Construction \\ Wuchang Shouyi University \\ Wuhan, China
}

\author{
Shouzeng Zhu \\ Department of Civil Engineering and Architecture \\ Guilin University of Technology \\ Guilin, China
}

\begin{abstract}
Fourteen classes majored in civil engineering were given lectures of Special English in Wuchang shouyi University. They were grouped in two, one was taught in interruption method by giving an assignment of preparing PPT for the lecture to see how they perform before and after that. The other eight were taught in development method which derived from the former and went further by providing more chances to get involved in class. The whole experiment shows that getting students involved by taking part in class is an effective way to prop up their interest in learning, thus improving their performance in class and tests.
\end{abstract}

\section{Keywords $\longrightarrow$ special English; dictation; performance}

\section{INTRODUCTION}

English teaching in fields beyond itself proves to be not quite successful in China despite of the fact that English majored students and teachers are proficient in this world language. The situation is sever in all other majors especially in boy-related engineering majors such as civil engineering, mechanical engineering, computer engineering, information engineering and so on. Since the deepening of globalization, English has become more and more indispensable in various kinds of communication between different countries and cultures. Thus majors aforementioned and not mentioned have now lectures conducted in English. Take civil engineering for instance, special English teaching only began around a decade ago. In a survey of four universities based on information derived from the internet, one thing is clear that students do not want to learn English besides current college English class already in the curriculum. That puts on more challenge to the assigned lecturer not only to give out lectures in a second language or even third language but also to heighten the focus and interests of students in and out of class.

The main weight of this class is placed on new words memorization and translation of long, difficult academic sentences. Ranging from 24 to 32 class periods, it is likely that students will not learn what they should in such a way. They also need to take on mutual understanding of the development of this globally important major in both languages as well as in its history, status quo and prospect. Many complained the lecturer neglected the fact that English is not an official language in Chinese mainland, most students in engineering related majors are rather poor at listening, speaking or writing in this language, not to mention effectively absorbing all the contents from class. Communication between lecturers and students was not sufficient so that students can not concentrate on the subject intangible for a long time. We have observed parched class soaked in boring air for so many years and changing the usage of language would not make too much difference[1]. Examinations and the homework also display the not charming attraction to students.

\section{ANALYSIS OF FEASIBILITY}

\section{A. Comparison between China and Overseas}

This is not the sole phenomenon exists in China. In our neighbor, Japan, which also regards English as a second language, having a similar situation in lingual education. Universities provide major-related lectures in English during graduate and postgraduate study. I walked into classrooms to communicate with students from different backgrounds only to find that most Asian countries, Japan, Korea, Myanmar, Laos, Cambodia, Thailand and so on, treat special English of this major the same way as we do. It is secondary to more professional lectures like Advanced Math or Engineering Mechanics, students learn special English by their own interest and efforts outside class. Such general and over-spreading ignorance of special English education would consequently affect the growth of new generations of future engineers in this field[2]. Competitions between English-speaking countries and non-English-speaking countries would stay unfair due to the lack of such awareness. What may strikes us is that progress of such lectures and researches in universities and colleges could fall behind western countries just because of language barriers. They prevent the youth from taking bigger steps for higher achievements. More effective lectures of special English going 
into campus calls for more serious attention from educational institutions in China and other Asian countries.

\section{B. Preparation before Experiment}

Wuchang Shouyi University sets up the course of Special English of Civil Engineering in the penultimate semester. According to the syllabus of the department of Urban Construction, after previous semesters of college English training in class, students are believed to have conquered preliminary obstacles of listening, reading, writing and speaking in English, which gives them relatively firm bedrock to continue learning that of specialized fields. Textbook chosen for lectures is one of the earliest that has been highly rated and frequently used by lots of universities and colleges.

Special English of Civil Engineering, published by Press of Wuhan University of Technology, comprising 244 pages within 22 different chapters bridging nearly every sector of the major. Each chapter has one passage of main text and two passages of advanced reading materials. In the end of each text, there lists all important words and phrases from the text, along with a couple of sentences in both Chinese and English that maybe too long or too deep for fresh learners. Insufficient time of 24 periods makes only 15 classic chapters out of 22 our main focus for detailed lecturing. "Table I" The 7 chosen chapters have covered the most significant branches of civil engineering, including buildings, bridges, roads, geotechnics, foundations, construction, calculations, design, and CAD. Students showed stronger interest and a short time of trifle malajustment when learning new chapters at the same time. It was the same situation when given assignments. That means when judge the results of the experiment, the malajustment factor should be considered, and the whole tendency may occupy heavier weight.

TABLE I. CHOSEN CHAPTERS For Class

\begin{tabular}{|l|l|}
\hline \multicolumn{1}{|c|}{ Chapters } & \multicolumn{1}{|c|}{ The me } \\
\hline Chapter 1 & Civil Engineering \\
\hline Chapter 2 & Building and Architecture \\
\hline Chapter 3 & Components of A Building \\
\hline Chapter 5 & Environmental Engineering \\
\hline Chapter 7 & Bridge \\
\hline Chapter 8 & Bridge Design and Construction \\
\hline Chapter 11 & High Engineering \\
\hline Chapter 13 & Underground Space Utilization \\
\hline Chapter 15 & Soil Mechanics \\
\hline Chapter 16 & Foundations \\
\hline Chapter 17 & Construction Engineering \\
\hline Chapter 18 & Building Materials \\
\hline Chapter 19 & Structural Analysis \\
\hline Chapter 20 & Structural Design \\
\hline Chapter 21 & Computer-Aided Drafting and Design \\
\hline
\end{tabular}

After one cycle of lectures, characteristics of this textbook is confirmed that new words along with super long sentences are the most difficult parts for fresh learners. 40 to even 60 words within one sentence is not unusual. Except that, a large part of understanding the contents of the textbook is contributed to grammars derived from lingual study from high school and the first two college years. All these push the lecturers to transform from traditional educators who follow the English-Chinese translation tradition to the ones who can improve the ability of sensitization of a bilingual learning [3].
The job requires purposely embracing students into class, valuing their activeness and spontaneity by paying attention individually as much as possible, improving their interest by getting them involved in lecture preparation, in taking part in activities such as short speech, translation of English songs and classic lines from familiar movie clips, and film appreciation.

\section{Prerequisites}

- One lecturer was assigned to give out lectures to all 14 classes in two semesters. The first group was taught in spring semester and the second group in fall semester.

- According to the previous teaching experiences, all lectures were conducted through the means of PPT which proves to be accepted more easily by students and attract their attention more effectively, thus improving their performance in class and exams[4][5].

- All lectures of Special English of civil engineering were given out at similar time for either group, the first 4 weeks of the semester so that it could decrease the difference possibly created by human reactions to weather, season or time change[6].

- Other factors which might affect the experiment for better accuracy and more practical comparison should be excluded, such as lecture arrangements, lecturing speed, methods of judgments both in and after class, new words for dictation, and the assignments for the students.

- Comparison between two semesters is also important since how to lecture in the fall semester depends on the results of the experiment of the spring semester. The develop method is the extension and derivation of the interruption method.

\section{PROCESS OF THE EXPERIMENT}

\section{A. Dictation}

Dictation without advance announcement is proved to be one of the best ways to test how students learn from the class because new words explanation is the main focus in those lectures. It was conducted at the beginning of every class except the first one. Words choice were random, but it contains both hard and comparatively easy ones. To make this more clear, a few words are listed in the following. Civil engineering, facility, environment, pipeline, quantity from chapter 1; architecture, aqueduct, activity, the elements from chapter 2; soil mechanics, weathering, foundation, clay, data from chapter 15; concrete, gravel, cement, shrink, hydration, moist from chapter 18 . Scores were put into a file in which average scores were calculated.

\section{B. Interruption Method}

After a couple of classes, students began to lose their interest and excitement observed from the very beginning really fast. If nothing was done, it continued to be dry and boring for both parties. Students would not rise to the expectation lecturers set for them spontaneously, who become more and more important in teaching fields since they are the 
ones who listen to the lectures after all. If lecturers neglect their practical responses without paying attention to the fluctuation of their initiatives in class, there will definitely be increasingly larger gap of communication between them. Learning of special English can lead to nowhere.

Thus interruption method came to practice. In the end of the second week, the middle of the whole course, students were assigned a task to prepare PPT materials with their own choice of teaming partners. Some did it all by himself or herself, some did it with other classmates. During the third week, 18 files were collected from six classes. At the same time, dictation went on without break. Scores of dictations are in "Fig. 1 ”.

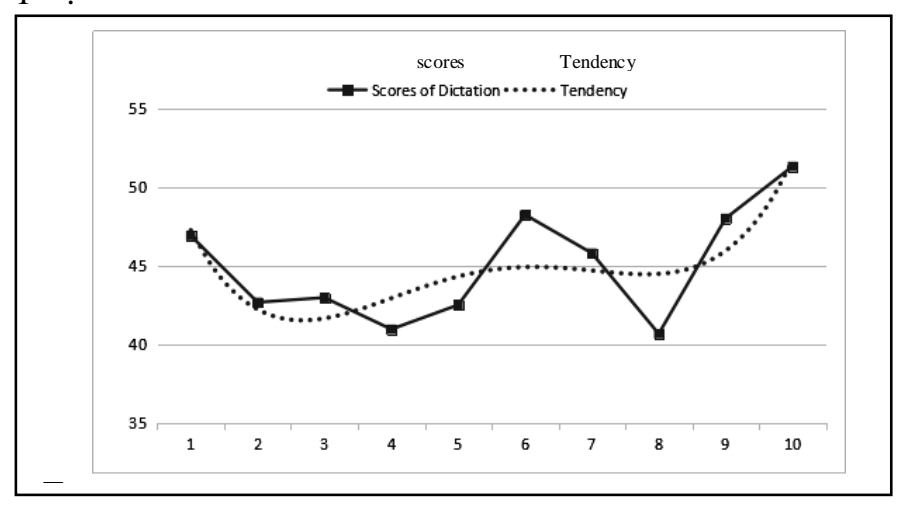

Fig. 1. Lines of scores in fall semester.

The block line in "Fig. 1" shows the average score of each dictation. As can be seen from the first four, scores are declining. It practically represents the situation in the class. Students were quite excited in the very first class, everybody was trying to hear every word came from the lecturer, trying to see every slide of PPT. But the textbook did not give back the same enthusiasm due to those very big and difficult new words and unbelievably long sentences. Take the first sentence of the first paragraph in chapter 1 for example. Civil engineering, the oldest of the engineering specialties, is the planning, design, construction, and management of the built environment. 8 new words in a 19-word-long sentence, and if you extract all the prepositions and copulas, the ration of new words to familiar words in one sentences is up to $72.7 \%$, not to mention the more complicate ones. This hard strike easily pulls down the confidence of fresh learners. When the assignment was given out in the end of the fourth class, students began to show more interest in the class again.

The task was to complete a PPT file containing at least 5 pages. The content was asked to be extracted from the textbook Since the fifth class, dictation showed better results which also resembles the score of "Fig. 1". One week later, after the deadline, students seemed to go back to the state where they were in the first two weeks. The completion of the assignment gave them an opportunity and enough excuse to relax. Dictation scores in the figure show the exact situation during class. What was worse, dictation proved to fall faster than before, and finally hit bottom in the eighth time. Reasons could not be found out until the last two hikes to the top. The dotted line in "Fig. 1" is the tendency line of all dictations, which puts out the same estimation of dictation scores. After the assignment, students had better performance in dictation and learned better in class.

\section{Development Method}

Conclusions above gave after thoughts like how to sustain students' enthusiasm, how to prevent declines this dramatic like the eighth time in "Fig. 1". So development method was put into practice. Obviously getting students involved in class, emphasize their sense of importance and driving force of the class was proved to be successful in mutual communication. Questions like what is on their mind to do in class, what to do is more interesting were asked in class. The most frequent answers came to points like watching movies or videos related to the class. New experiment then was conducted in fall semester by inheriting useful lessons from the semester before and incorporating new ways like translation of classic lines in classic film clips, bilingual translation of English songs, short speeches and movie appreciation.

From "Fig. 2" we can see the tendency line is smoother than that of "Fig. 1'. It shows that development method could sustain interest of students, decrease the possibility to hit the bottom lecturers are trying to avoid, like the eighth time in "Fig. 1 " Another place shows the improvement of this method is their average score. Interruption method group has an average score of 45.0, a score lower than passing line, while the development method group has an average score of $61.6,16.6$ points higher than the former.

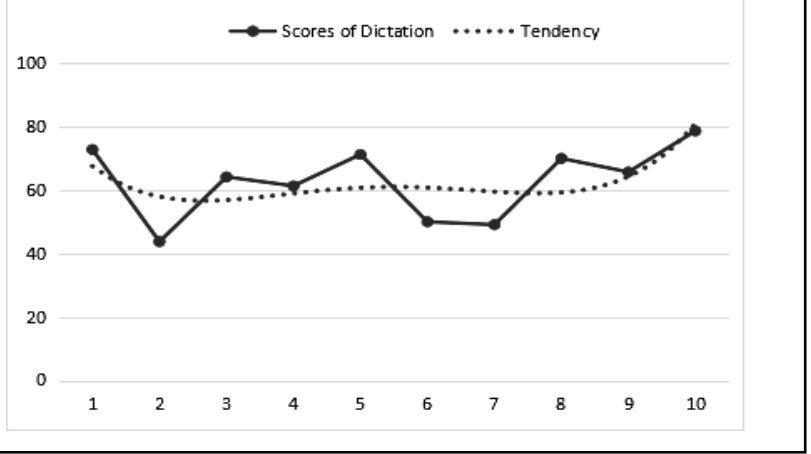

Fig. 2. Lines of scores in spring semester.

Judgments of performance of students in class were mainly subdivided into three parts, responses to questions during lectures, eye contact communication between students and the lecturer, results of dictations with no advance announcements. The first two parts need the lecturer to pay sufficient focus and rigorous observation, along with careful comparison. Even though Special English of Civil Engineering rouses much passion of the fresh learners in the beginning because of its relativity to their own major in such a different way, continuously stimulating activeness and serious efforts is pretty much an impossible task. So getting them involved is one of the available ways to keep their interests in learning. To make lectures interesting, at the same time keep the diversity of them is essential to prompt students to get involved in something seems fun and has much to learn. To present beautiful pictures of the buildings, bridges and other civil engineering structures from related texts would be useful. The third part, dictation, is 
chosen because its direct and clear results can mathematically show how well students perform. The process was taken out by the same amounts of the same words for each class. In order to make the results creditable and authentic, the lecturer made sure to keep eyes on students to minimize cheating and call up every name on the submitted paper afterwards to eliminate frauds. Dictation scores can be used to check the degree of correctness of the first two parts.

\section{CONCLUSION}

Special English learning goes into the curriculum of college is an inevitable tend and necessary request of the new-round globalization of information and communication. It spans over many fields, including medical theory, mechanical engineering, civil engineering, information technology and so on. Through lectures, a broader horizon and more international view of the major would be imparted to students, which prepares those future professionals who are going into practice immediately after graduation. Thus making communications between the lecturer and students more effective becomes a major task for class and more importantly for the whole specialized education Combine observation in class and results of dictations, a useful conclusion was drawn as follows.

- Real time observation in class shows that most students especially in Engineering majors do not have much interest and motivation in special English learning. Lectures better start after all College English classes are finished since the latter gives sufficient lingual education to students for easier access to the former. In Wuchang Shouyi University, this class has been arranged in the $6^{\text {th }}$ or the $7^{\text {th }}$ semester, giving one or two whole semesters of blank period of lingual contacts for students. This only puts more pressure on them to get into it. Consistency is important.

- Lines in "Fig. 1" and “Fig. 2" resemble the performance of students in class which proves that dictation is a practical way to judge how well students learn and how much efforts they pay during and after class. Tendency Line in "Fig. 1" shows their interest was climbing after getting involved in preparation for lectures that they may have a chance to be a part of. Tendency Line in "Fig. 2" hows incorporating new ways such as watching movies or videos related to the class, translation of classic lines in classic film clips, bilingual translation of English songs, short speeches and movie appreciation can be useful in sustaining interest of them. But how often should these parts be conducted in class remains unclear. Next semester similar experiment would be done to figure that out.

- Even though the situation of special English learning is not very positive right now in China and in most Asian countries, development of lectures and teaching methods can push the progress of bilingual classes. Getting students involved is not something new in education, you can see that classes of philosophy disciplines. Applying their successful experience to classes in engineering fields is a new start of a new era of engineering education.
- There will be more and more international opportunities for students and specialized staff in any country under present economic environment, lessons from this article may offer some reference value for special English education.

\section{REFERENCES}

[1] J. Dongyun, "Reflection on teaching special English of civil engineering," Journal of Anhui University of Technology, 2006, pp. 9697.

[2] Z. Lijuan, C. Longlong, "Discussion about revolution in modes of teaching special English of civil engineering," College Education, 2014, pp. 93-94.

[3] H. Wei, Q. Juyun, and B. Zhe, "Innovation and exploration in teaching special English of Civil Engineering," Heilongjiang Education, 2016, pp 25-26.

[4] T. Jianping, "Application of PPT and blackboard in lectures," History Education, 2008, pp: 21-22.

[5] Information on http://news.univs.cn/2012/0509/921989.shtml.

[6] P. Zhijia, Z. Shouzeng, "Practical comparison between teaching methods of blackboard and PPT in special English of Civil Engineering," Higher Education Forum, 2015, pp. 81-84. 